EPJ Web of Conferences 82, 01059 (2015)

DOI: $10.1051 /$ epjconf/20158201059

(C) Owned by the authors, published by EDP Sciences, 2015

\title{
Cross-correlation video recording of gas-vapor-droplet two-phase flows
}

\author{
Roman S. Volkov, Olga V. Vysokomornaya, Alyona O. Zhdanova and Pavel A. Strizhak \\ National Research Tomsk Polytechnic University, 634050 Tomsk, Russia
}

\begin{abstract}
The experimental investigations of gas-vapor-droplet two-phase flow formation during single water droplets and their aggregate motion through high-temperature (more than $1000 \mathrm{~K}$ ) combustion products have been conducted with usage of crosscorrelation measuring facility and optical methods of "tracer" visualization ("Particle Image Velocimetry" and "Interferometric Particle Imaging"). Modes of droplet motion in high-temperature gases area have been established. It has been determined the influence of the main droplet (sizes, composition, temperature, dispersability, form, velocity) and gas (temperature and velocity) characteristics on parameters of forming gas-vapor-droplet mixtures. The main elements of advanced firefighting technologies with the usage of time and space apportioned polydisperse composition water droplet flows have been formulated. Physical and predictive mathematical models have been developed to determine the basic parameters of equipment which is necessary for operation with these technology usage.
\end{abstract}

\section{Introduction}

The idea of using in fire-fighting of the dispersed phlegmtizators of burning, especially water mist, received recently quite extensive discussion. There are many arguments, both in support, and against the use of systems on the basis of water mist at ignitions localization. However the last theoretical and experimental [1-7] researches practically didn't leave doubts in efficiency of water mist using in comparison with traditional fire extinguishing technologies. One of the major aspects increasing the efficiency of water mist using in firefighting, is the intensification of the process of its evaporation in the field of a flame. Therefore, research of the process of water mist evaporation in the flame field with the use of modern diagnostic methods, and also influence of water parameters (component structure, initial temperature, rate, the sizes of droplets in a flow) on the characteristics of this process is of special interest.

The purpose of this work - experimental research of the process of two-phase gas-vapor-droplet flows formation at movement of water droplets in the field of high-temperature combustion products, and also the ranges establishment of influences of the water mist initial parameters on this process.

\footnotetext{
${ }^{a}$ Corresponding author: pavelspa@tpu.ru
}

This is an Open Access article distributed under the terms of the Creative Commons Attribution License 4.0, which permits unrestricted use, distribution, and reproduction in any medium, provided the original work is properly cited. 


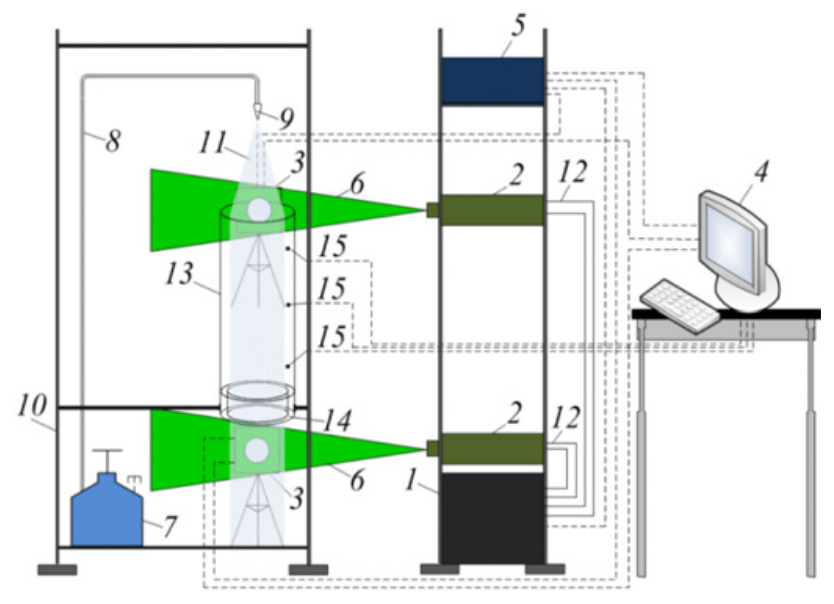

Figure 1. A scheme of experimental setup: 1 - laser emission generator; 2 - double pulsed solid-state laser; 3 - cross-correlation digital camera; 4 - PC: personal computer; 5 - synchronizer of PC, cross-correlation digital camera and laser ; 6 - light "pulse"; 7 - vessel with experimental liquid; 8 - channel of experimental liquid supply; 9 - atomizer (dosing device); 10 - tripod; 11 - experimental liquid droplets; 12 - cooling liquid channel of laser; 13 - heat-resistant cylinder; 14 - hollow cylinder with combustible liquid in internal medium ; 15 - thermocouples.

\section{Experimental setup and procedure}

The experimental setup (Fig. 1) was used in carrying out of experimental researches. The experimental stand is a modern high-precision system of two-phase gas-, vapor-liquid streams diagnostics, working at the base of non-contact optical methods of "tracer" visualization such as "Particle Image Velocimetry" (PIV) and "Interferometric Particle Imaging" (IPI) [8-10]. The experimental setup (Fig. 1) on the basic elements is similar to that [5-7] used and includes: cross-correlation digital camera with figure format $-2048 \times 2048$ pixels, frame frequency - not less than $1.5 \mathrm{~Hz}$, minimal delay between two sequence figures - not more than $5 \mathrm{~ms}$; double pulsed solid-state laser with an active area of "yttrium aluminum garnet" and neodymium additives which has the wave-length $-532 \mathrm{~nm}$, energy in impulse - not less than $70 \mathrm{~mJ}$, impulse time - not more than $12 \mathrm{~ns}$, recurrence frequency - not more than $15 \mathrm{~Hz}$; synchronizing processor with signal sampling - not more than $10 \mathrm{~ns}$ and supporting the external and internal triggering modes.

The technique of carrying out experiments included the following procedures. The kerosene $(250 \mathrm{ml})$ was filled with interwalled space of the cylinder. After that, it was placed at the base of the heat-resistant translucent cylindrical channel. The ignition of kerosene started before the experimentation. The internal space of the channel was filled by high temperature combustion products generated during the burning of kerosene. After the set time (280 seconds), necessary for heat-up of inner cylinder cavity up to the average temperatures of a typical fire $(1070 \pm 30 \mathrm{~K})$, water from vessel through the channel was pumped on an entrance of the atomizer. Then input of liquid droplets to the channel filled with high-temperature combustion products was carried out. By means of light "pulse" a trajectory of droplet movement was illuminated. Procedure for video registration of droplets was carried out by a cross-correlation digital camera. Video images were transferred to the personal computer (PC). Then, according to techniques [8-10], the instant distributions of rates and the sizes of the sprayed liquid droplets on an entrance and an exit from the channel were defined.

Droplet sizes in registration areas (on an inlet and outlet of channel 13) were defined by means of the IPI method. Instant velocity fields of the dispersed liquid flow were constructed using the PIV method. 
As a working liquid (similar to experiments [5-7]) water with nanopowder particles of the titanium dioxide was used. Titanium dioxide nanopowder about $0.5 \%$ by weight was added into the water immediately before the experimentations for a videogram contrast rise upon the laser illumination. The choice of $\mathrm{TiO}_{2}$ power as the "tracers" was conditioned by that fact that its particles did not dissolve in water and did not influence on vaporization.

All experimental cycles have been divided into several stages. At the first stage the influence of impurities of salt water droplets on the completeness of its evaporation was defined when they were moving through a flame zone. $\mathrm{NaCl}$ salt was used. The mass fraction $(\gamma)$ of salt in solution changed in the range of $0 \div 0.05$. At the second stage the influence of the initial temperature of the working liquid on characteristics of its evaporation was defined. The initial temperature $\left(T_{\mathrm{w}}\right)$ of liquid in experiments changed in the range of $293 \div 323 \mathrm{~K}$. At the third stage the influence of initial rates of the dispersed liquid flow on the process of its evaporation was estimated. Initial rates of droplets $\left(U_{\mathrm{m}}\right)$ in a flow changed from 0.8 to $1.4 \mathrm{~m} / \mathrm{s}$.

For an assessment of completeness of working liquid evaporation when droplets were moving through a flame area the integrated $\Delta R$ parameter was entered:

$$
\Delta R=\frac{R_{\mathrm{m}}^{\mathrm{BX}}-R_{\mathrm{m}}^{\mathrm{BbIX}}}{R_{\mathrm{m}}^{\mathrm{BX}}} \cdot 100,
$$

where $R_{\mathrm{m}}^{\mathrm{BX}}, R_{\mathrm{m}}^{\mathrm{BbIX}}$ - the value of average characteristic radius of liquid droplets at the inlet and outlet of the cylindrical channel, $\mathrm{mm}$.

Gas (combustion products) temperature in the cylindrical channel was controlled by chromel-alumel thermocouples (temperature measurement range $273 \div 1373 \mathrm{~K}$, the tolerance $\Delta=3.3 \mathrm{~K}$ ) at different height levels $(0.15 \mathrm{~m}, 0.5 \mathrm{~m}, 0.85 \mathrm{~m})$ and was $1070 \pm 30 \mathrm{~K}$. Working fluid temperature in the vessel was controlled by chromel-copel thermocouples (temperature measurement range $233 \div 573 \mathrm{~K}$, the tolerance $\Delta=2.5 \mathrm{~K}$ ). The thermocouple measurement procedure similar to experiments [5, 7] was used. Known techniques of thermocouple measurements were used [11].

Systematic errors in gas and liquid temperature measurements did not exceed $2.5 \%$ [12], "tracer" velocities $-2 \%[8,9]$, droplet sizes $-1.5 \%$ [10].

\section{Results and discussion}

During experimental investigations the influence of previously identified factors to completeness of liquid evaporation in the flame zone has been evaluated. Figure 2 shows the influence of salt impurities on dispersed water droplets evaporation intensity.

It has been determined, that mass fraction increase $\gamma$ of salt $\mathrm{NaCl}$ in water causes a slight (within $10 \%$ ) reduction in evaporation intensity. This feature should be considered in case of using water from various natural ponds as a quenching liquid, which salt content can range $0-100 \mathrm{~g} / \mathrm{l}$.

When designing fire-extinguishing systems, there is also often not taken into account the initial temperature $T_{\mathrm{w}}$ of quenching fluid, capable to vary widely depending on ambient temperatures. Thus, Figure 3 illustrates the effect of initial water temperature to the intensity of its evaporation in the flame zone. It can be seen (Fig. 3) that the initial temperature $T_{\mathrm{w}}$ increase in the range of $293 \div 323 \mathrm{~K}$ in several times intensifies atomized water evaporation.

Another important factor to be considered in the development of fire extinguishing appropriate tools and fire systems is, undoubtedly, the initial flow liquid spray velocity $U_{\mathrm{m}}$. Thus, according to the results of the experiments (Fig. 4), it can be said about the moderate (within 5\%) effect of the initial droplet velocity on the completeness of their evaporation in a narrow speed range $(0.8 \div 1.5 \mathrm{~m} / \mathrm{s})$. In real fireextinguishing systems, where liquid spray droplet flow rate can often be tens of meters per second, it is possible to predict a significant increase in the contribution to the evaporation rates $U_{\mathrm{m}}$ completeness. 


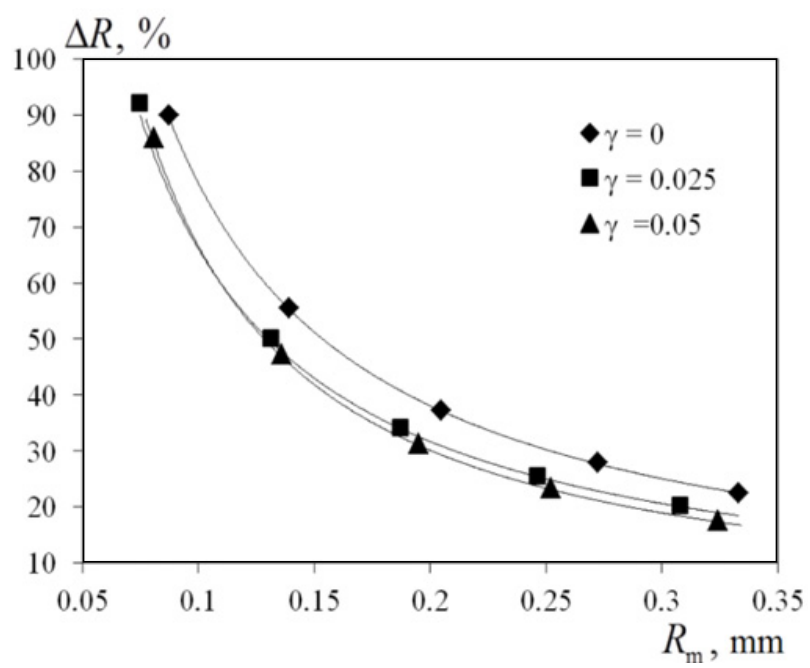

Figure 2. Dependence of $\Delta R$ parameter on the average initial droplet size $R_{\mathrm{m}}$ at various mass salt fractions $\gamma$ in the operating liquid solution $\left(T_{\mathrm{w}}=293 \mathrm{~K}, U_{\mathrm{m}}=0.8 \mathrm{~m} / \mathrm{s}\right)$.

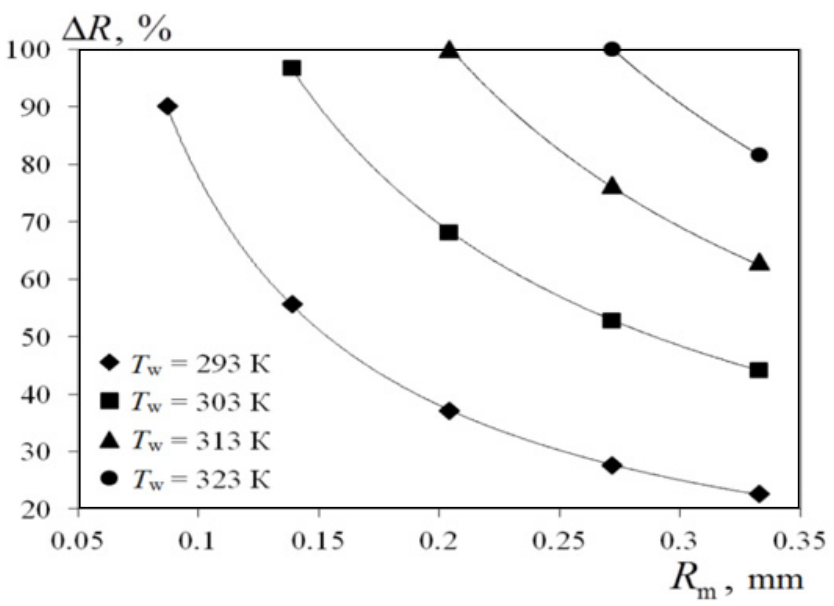

Figure 3. Dependence of $\Delta R$ parameter from average initial droplet sizes $R_{\mathrm{m}}$ at different initial working fluid temperatures $T_{\mathrm{w}}\left(\gamma=0, U_{\mathrm{m}}=0.8 \mathrm{~m} / \mathrm{s}\right)$.

Furthermore, as a result of experiments, it has been determined, that for the premises, where the flame height is usually does not exceed $1-2 \mathrm{~m}$, the rising combustion products speed is $0.3 \div 2 \mathrm{~m} / \mathrm{s}$ and the quenching liquid temperature in the fire-extinguishing system corresponds to the room temperature, drops with a characteristic sizes $R_{\mathrm{m}} \leq 0.15 \mathrm{~mm}$ almost fully exposed to reversal and subsequent entrainment with high temperature combustion products. At the same time, droplets with sizes $R_{\mathrm{m}}>$ $0.3 \mathrm{~mm}$ pass through the flame almost not being evaporated (Figs. 2-4).

Based on the foregoing, at the liquidation of fire in premises it can be recommended to use a polydisperse droplet flow, a significant part of which (above 50\%) should be the droplets with sizes $0.15<R_{\mathrm{m}} \leq 0.25 \mathrm{~mm}$. At prolonged exposure to a flame these droplets can penetrate into the combustion zone, and evaporate over there completely, to reduce its temperature below the temperatures of combustion structures and start the thermal decomposition of materials. But a contribution of droplets 


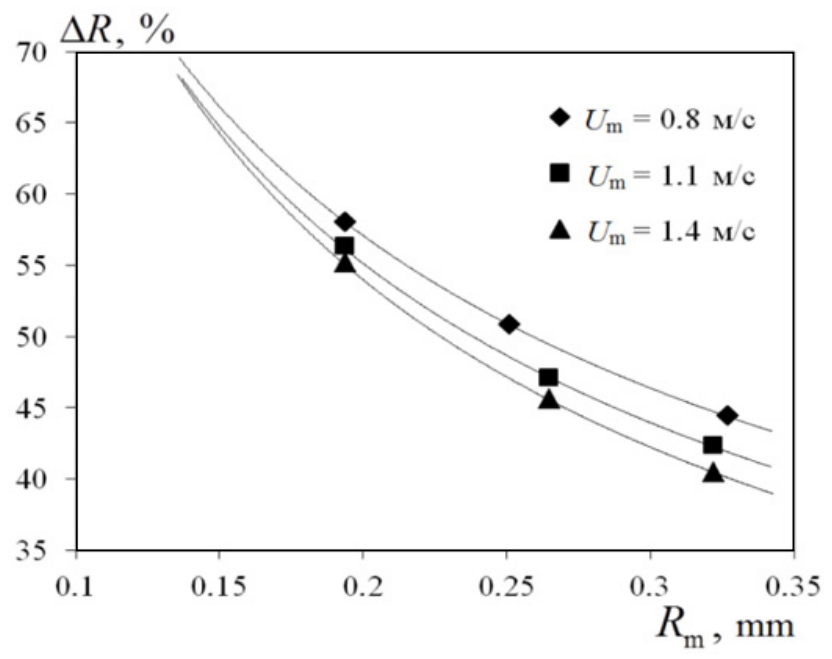

Figure 4. Dependence of $\Delta R$ parameter on the average initial droplet sizes $R_{\mathrm{m}}$ at different initial fluid flow velocities $U_{\mathrm{m}}\left(\gamma=0, T_{\mathrm{w}}=298 \mathrm{~K}\right)$.

with other sizes $\left(R_{\mathrm{m}} \leq 0.15 \mathrm{~mm}\right.$ and $\left.R_{\mathrm{m}}>0.25 \mathrm{~mm}\right)$ shouldn't be underestimated to process of fire extinguishing. Large droplets $\left(R_{\mathrm{m}}>0.25 \mathrm{~mm}\right)$ without special difficulties enter into the combustion zone. They reduce the draft developed by a fire, and provide further penetration into a combustion zone of smaller droplets. Besides, large droplets are capable to pass completely a flame and to irrigate burning surfaces and the surfaces not yet mentioned by a fire. Cooling of these surfaces prevents further spread of the flame. The smallest liquid droplets $\left(R_{\mathrm{m}} \leq 0.15 \mathrm{~mm}\right)$, absorbing soot particles, provided their sedimentation in the air. The gas-vapor-droplet mix formed as a result of these processes is capable to force out gradually an oxidizer from a fire zone.

According to the results of experimental investigations, a mathematical model has been complied, which describe the movement of water droplet groups in high-temperature gaseous environment. The mathematical model includes the following system of nonlinear time-dependent partial differential equations $\left(0<\tau<\tau_{\mathrm{d}}\right)$ :

$0<R<R_{L}, 0<Z<Z_{1}, Z_{2}<Z<Z_{3}, Z_{4}<Z<Z_{L} ; R_{1}<R<R_{L}, Z_{1}<Z<Z_{2}, Z_{3}<Z<Z_{4}$

$$
\begin{gathered}
\frac{1}{\text { Fo } 1} \frac{\partial \Theta_{1}}{\partial \tau}=\frac{\partial^{2} \Theta_{1}}{\partial R^{2}}+\frac{1}{R} \frac{\partial \Theta_{1}}{\partial R}+\frac{\partial^{2} \Theta_{1}}{\partial Z^{2}} ; \\
\frac{\partial \gamma_{\mathrm{w}}}{\partial \tau}=\mathrm{Gp}_{3}\left(\frac{\partial^{2} \gamma_{\mathrm{w}}}{\partial R^{2}}+\frac{1}{R} \frac{\partial \gamma_{\mathrm{w}}}{\partial R}+\frac{\partial^{2} \gamma_{\mathrm{w}}}{\partial Z^{2}}\right) ; \\
\gamma_{\mathrm{f}}+\gamma_{\mathrm{w}}=1 ; \\
0<R<R_{1}, \quad Z_{1}<Z<Z_{2}, \quad Z_{3}<Z<Z_{4} \\
01059-p .5
\end{gathered}
$$




$$
\begin{gathered}
\frac{1}{\mathrm{Fo}_{2}} \frac{\partial \Theta_{2}}{\partial \tau}=\frac{\partial^{2} \Theta_{2}}{\partial R^{2}}+\frac{1}{R} \frac{\partial \Theta_{2}}{\partial R}+\frac{\partial^{2} \Theta_{2}}{\partial Z^{2}} \\
\mathrm{Fo}_{1}=\frac{\lambda_{1} t_{\mathrm{m}}}{\rho_{1} C_{1} z_{\mathrm{m}}^{2}}, \quad \mathrm{Fo}_{2}=\frac{\lambda_{2} t_{\mathrm{m}}}{\rho_{2} C_{2} z_{\mathrm{m}}^{2}}, \quad \mathrm{Gp}_{3}=\frac{D_{3} t_{\mathrm{m}}}{z_{\mathrm{m}}^{2}} .
\end{gathered}
$$

Initial ( $\tau=0$ ) conditions: $\Theta=\Theta_{0}$ at $0<R<R_{\mathrm{L}}, 0<Z<Z_{1}, Z_{2}<Z<Z_{3}, Z_{4}<Z<Z_{\mathrm{L}} ; R_{1}<$ $R<R_{\mathrm{L}}, Z_{1}<Z<Z_{2}, Z_{3}<Z<Z_{4} ; \Theta=\Theta_{\mathrm{f}}, \gamma_{\mathrm{f}}=1, \gamma_{\mathrm{w}}=0$ at $0<R<R_{1}, Z_{1}<Z<Z_{2}, Z_{3}<$ $Z<Z_{4}$.

Boundary conditions: on "fluid - gas" borders $\left(R=R_{1}, Z_{1}<Z<Z_{2}, Z_{3}<Z<Z_{4} ; Z=Z_{1}\right.$, $Z=Z_{2}, Z=Z_{3}, Z=Z_{4}, 0<R<R_{1}$ ) boundary conditions of type II have been set for the diffusion equation, taking into account water vapor injection; on the external borders $\left(R=0, R=R_{\mathrm{L}}, 0<Z<\right.$ $Z_{\mathrm{L}} ; Z=0, Z=Z_{\mathrm{L}}, 0<R<R_{\mathrm{L}}$ ) the condition that corresponding function gradients are equal to zero has been assumed for all the equations. In contrast to the model [13] to account the influence of water vapor injection on heat transfer conditions at "fluid - gas" boundaries in accordance with the conclusions of [14] for energy equations the following boundary conditions have been set:

$$
\begin{gathered}
R=R_{1}, \quad Z_{1}<Z<Z_{2}, \quad Z_{3}<Z<Z_{4}, \\
\frac{\partial \Theta_{2}}{\partial R}=\frac{\lambda_{1}}{\lambda_{2}} \frac{\partial \Theta_{1}}{\partial R}-Q_{\mathrm{e}} W_{\mathrm{e}} \frac{z_{\mathrm{m}}}{\Delta \mathrm{T} \lambda_{2}}-\rho_{3} C_{3} V_{\mathrm{e}}\left(\Theta_{3 \mathrm{~s}}-\Theta_{2 \mathrm{~s}}\right) \frac{z_{\mathrm{m}}}{\lambda_{2}}, \\
Z=Z_{1}, \quad Z=Z_{2}, \quad Z=Z_{3}, \quad Z=Z_{4}, \quad 0<R<R_{1}, \\
\frac{\partial \Theta_{2}}{\partial Z}=\frac{\lambda_{1}}{\lambda_{2}} \frac{\partial \Theta_{1}}{\partial Z}-Q_{\mathrm{e}} W_{\mathrm{e}} \frac{z_{\mathrm{m}}}{\Delta \mathrm{T} \lambda_{2}}-\rho_{3} C_{3} V_{\mathrm{e}}\left(\Theta_{3 \mathrm{~s}}-\Theta_{2 \mathrm{~s}}\right) \frac{z_{\mathrm{m}}}{\lambda_{2}} .
\end{gathered}
$$

The equation of droplet motion in terms of vaporization, considering the forces of resistance and severity, according to the concepts of [15-17] has the following form:

$$
\frac{d v_{\mathrm{d}}}{d t}=\frac{3 \rho_{3}}{4 \rho_{2} 2 r_{\mathrm{d}}} c_{\chi}\left|v_{\mathrm{d}}-v_{\mathrm{e}}\right|\left(v_{\mathrm{d}}-v_{\mathrm{e}}\right)+g
$$

where $v_{d}(0)=v_{0}$.

Thus, obtained during experiments dependencies, and corresponding mathematical model, compiled on their basis, can describe considerably detailed the process of liquid droplet evaporation, moving in a high-temperature gas environment, taking into account a number of factors. These investigations should be taken into account in the prognostic assessment of evaporated liquid percentage at operating of fire extinguishing tools and systems.

\section{Conclusions}

1. Ranges of the basic dispersed water droplets parameters (initial velocity, sizes, component composition and fluid temperature) which influence on the evaporation process in hightemperature combustion products have been experimentally determined. 
2. It has been shown, that for the most efficient use of water spray at fire liquidation in the premises is the use of polydisperse drop flow, the main part of which (at least 50\%) is droplets with sizes $0.15<R_{\mathrm{m}} \leq 0.25 \mathrm{~mm}$.

3. A mathematical model has been developed. This model describes the evaporation processes of liquid droplets during their motion in a high-temperature gas environment, which allows to make a predictive assessment of evaporating water proportion, taking into account experimentally identified features.

4. The received physical and predictive mathematical models should be applied to determine the basic parameters of equipment, operating in fire-extinguishing systems based on water mist.

This work was supported by the Russian Science Foundation (No. 14-39-00003).

\section{References}

[1] B. Yao, B.H. Cong, J. Qin, W.K. Chow, Fire Safety Journal 47, 32 (2012)

[2] Na Meng, Longhua Hu, Shuai Liu, Long Wu, Longfei Chen, Binghai Liu. Journal of Fire Sciences 30, 138 (2012)

[3] M. Guptaa, R. Rajoraa, S. Sahaia, R. Shankar, A. Ray, S.R. Kale, Fire Safety Journal 54, 130 (2012)

[4] D.O. Glushkov, G.V. Kuznetsov, P.A. Strizhak, Math. Prob. Eng. 2014, 920480 (2014)

[5] R.S. Volkov, G.V. Kuznetsov, P.A. Strizhak, Journal of Engineering Physics and Thermophysics 87, 450 (2014)

[6] R.S. Volkov, O.V. Vysokomornaya, G.V. Kuznetsov, P.A. Strizhak, Journal of Engineering Physics and Thermophysics 86, 1413 (2013)

[7] R.S. Volkov, O.V. Vysokomornaya, G.V. Kuznetsov, P.A. Strizhak, Adv. Mech. Eng. 2014, 865856 (2014)

[8] R.D. Keane, R.J. Adrian, Applied Scientific Research 49, 191 (1992)

[9] J.M. Foucaut, M. Stanislas, Measurement Science and Technology 13, 1058 (2002)

[10] T. Kawaguchi, Y. Akasaka, M. Maeda, Measurement Science and Technology 13, 308 (2002)

[11] Yu.V. Polezhayev, F.B. Yur'yevich, Thermal protection (Energiya Publ., Moscow, 1976) [in Russian]

[12] A.N. Zaydel', Simple estimates of measurement errors (Nauka Publ., Leningrad, 1968) [in Russian]

[13] P.A. Strizhak, Journal of Engineering Physics and Thermophysics 86, 895 (2013)

[14] B.M. Pankratov, Y.V. Polezhaev, A.K. Rud'ko, Interaction of materials with gas flows (Engineering, Moscow, 1976) [in Russian]

[15] Basset A.B. On the motion of a sphere in a viscous liquid (Phil. Trans. Roy. Soc. Lond, 1888)

[16] Boussinesq J.V. Sur la resistance d'une sphere solide (C.R. Hebd. Seanc. Acad. Sci. Paris, 1885)

[17] Oseen C.W. Hydromechanik (Akademische Verlagsgem, Leipzig, 1927) 